\title{
Adhesion and friction performance of DLC/rubber: The influence of plasma pretreatment
}

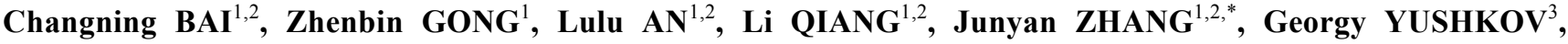 \\ Alexey NIKOLAEV ${ }^{3}$, Maxim SHANDRIKOV ${ }^{3}$, Bin ZHANG ${ }^{1,2, *}$ \\ ${ }^{1}$ Key Laboratory of Science and Technology on Wear and Protection of Materials, Lanzhou Institute of Chemical Physics, \\ Chinese Academy of Sciences, Lanzhou 730000, China \\ ${ }^{2}$ Center of Materials Science and Optoelectronics Engineering, University of Chinese Academy of Sciences, Beijing 100049, \\ China
}

${ }^{3}$ High Current Electronics Institute, Russian Academy of Sciences, Tomsk 634055, Russia

Received: 27 November 2019 / Revised: 01 April 2020 / Accepted: 30 July 2020

(C) The author(s) 2020 .

\begin{abstract}
Diamond-like carbon (DLC) films are deposited on rubber surfaces to protect the rubber components, and surface pretreatment of the rubber substrates prior to the film deposition can improve the adhesion between the DLC films and the rubber. Thus, the principal purpose of this work concentrates on determining the effects of argon (Ar), oxygen $\left(\mathrm{O}_{2}\right)$, nitrogen $\left(\mathrm{N}_{2}\right)$, and hydrogen $\left(\mathrm{H}_{2}\right)$ plasma pretreatments on the adhesion and friction performance of the DLC films deposited on rubber (DLC/rubber). The results indicated that the Ar plasma pretreatment promoted the formation of a compact layer on the rubber surface. By contrast, massive fillers were exposed on the rubber surface after oxygen or nitrogen plasma pretreatments. Moreover, the typical micrometer-scale patches divided by random cracks were observed on the surface of DLC/rubber, except for the sample pretreated with oxygen plasma. The adhesion of DLC/rubber was found to strengthen with the removal of weak boundary layers and the generation of free radicals on the rubber surface after plasma pretreatment. The tribo-tests revealed that DLC/rubber with $\mathrm{O}_{2}, \mathrm{~N}_{2}$, and $\mathrm{H}_{2}$ plasma pretreatments cannot achieve optimal friction performance. Significantly, DLC/rubber with Ar plasma pretreatment exhibited a low and stable friction coefficient of 0.19 and superior wear resistance, which was correlated to the high adhesion, good load-bearing of the rubber surface, and the approximate sine function of the surface profile of the DLC film.
\end{abstract}

Keywords: diamond-like carbon (DLC) films; rubber; plasma pretreatment; adhesion; friction

\section{Introduction}

Friction and wear of rubber against rigid surfaces are important topics in the automotive (sealing, bushing), construction (roofing), and electronic (insulators) industries. Optimizing the friction performance of rubber components has been shown to contribute to minimized energy loss, increased overall efficiency of machines, and the prevention of sealing fluid leakage $[1,2]$. Particularly, many rubber components operate in unlubricated or lubricant-lacking environments. For example, the inlet gap of the contact zone cannot be completely filled with the lubricating medium at the startup of the reciprocating seal [3, 4]. Additionally, deteriorated metal counterpart surfaces and intruding external particles can promote surface crack propagation, and scratching

* Corresponding authors: Junyan ZHANG, E-mail: zhangjunyan@licp.cas.cn; Bin ZHANG, E-mail: bzhang@licp.cas.cn 
and plowing of rubber surfaces [5, 6]. Therefore, investigations aimed at preventing rubber components from undergoing serious friction and wear are considered top priority projects.

Diamond-like carbon (DLC) films have garnered considerable interest as materials for lubrication and protection, due to the combination of relatively high hardness, ultralow friction, and excellent wear resistance [7-9]. Beyond that, DLC films not only possess promising chemical compatibility with the rubber (to prevent the degradation of rubber components) but the deposition temperature can be adjusted to be lower than the upper temperature limit of the rubber (by the choice of the deposition method and controlling process variables) [10-13]. Therefore, DLC films prepared on the rubber surface is undoubtedly a viable option. However, when a rigid protective film is deposited on flexible rubber substrates, interfacial delamination under load conditions is inevitable. To overcome this limitation, plasma modification of the rubber surface has been developed to improve the adhesion between the DLC films and rubber.

The improvement in adhesion between the DLC films and rubber by plasma pretreatment can be attributed to several major factors, including the removal of low molecular weight substances to obtain cleaned surfaces, the synergistic effects of chain scission and crosslinking, the generation of free active species on the upper surface, and the modification of the chemical structure and morphology of the rubber surface [14]. The adhesion of DLC/rubber was shown to increase by using $\mathrm{Ar}$ or $\mathrm{Ar}-\mathrm{H}_{2}$ plasma [15]. Moreover, a relationship between the film patch size and the adhesion strength has been established [16-19]. Furthermore, a multitude of research on $\mathrm{O}_{2}$ plasma pretreatment for improving the strength of adhesion has been carried out. On the one hand, $\mathrm{O}_{2}$ plasma can react with the rubber surface to form new functional groups, such as $\mathrm{C}-\mathrm{O}, \mathrm{C}=\mathrm{O}$, $\mathrm{O}=\mathrm{C}-\mathrm{O}$ or even more exotic groups [20]. On the other hand, $\mathrm{O}_{2}$ plasma can produce more significant ablation of the rubber surface, which can result in the entire removal of the oil layer [21].
Although considerable efforts have been devoted to the studies of DLC/rubber adhesion, a comparative study on the effects of various plasmas on DLC/rubber adhesion has not been reported, which can be critical for selecting the appropriate plasma pretreatment.

Another important concern of DLC/rubber is their friction behavior. Generally, excellent friction performance can be achieved by avoiding the adhesive force by depositing inert DLC films, improving the adhesion between the DLC films and rubber, forming a high density of crack (small patch size), and generating a transfer layer during friction [22-25]. It is understandable that a smaller patch size has a lower probability of fracture during loading/sliding and endows DLC/rubber with better flexibility [26]. In addition, the effect of rubber roughness on the friction performance of DLC/rubber has been studied [27]. It was found that superior wear resistance can be obtained by depositing DLC films on rough/grainy rubber surfaces. By contrast, the relatively smooth rubber surface has a detrimental effect on the friction and wear performance of DLC/rubber [27]. Although the friction behavior has been extensively studied from the perspective of DLC films and rubber substrates, the relationship between plasma pretreatment and the friction performance of DLC/rubber is unclear.

In this work, the influence of different plasma pretreatment on the adhesion and friction behaviors of DLC films deposited on nitrile butadiene rubber (NBR) was studied, with the aim of identifying the optimal plasma pretreatment. The adhesion between the DLC films and NBR substrates was determined by applying the X-cut method [28] and scratch test using GCr15 steel balls (ø6 mm) as counterparts [29]. The friction performance of DLC/rubber was investigated via the ball-on-disk tribo-tests under $10 \mathrm{~N}$ loads to accelerate wear.

\section{Experimental details}

\subsection{Sample preparation}

A black NBR sheet of $2 \mathrm{~mm}$ thickness with Shore A 
hardness of $80 \pm 5$ was provided by Northwest Rubber Plastics Research and Design Institute Co. Ltd. (Xianyang, China). Before the plasma pretreatment, the substrates were cleaned by soapy water and boiling water, and then dried under air flow. Plasma pretreatment of the NBR substrates and the deposition of DLC films were carried out via a plasma enhanced chemical vapor deposition (PECVD) system. The NBR substrates were placed on the substrate holder and transferred into the chamber, and then the vacuum chamber was pumped to $1.0 \times 10^{-3} \mathrm{~Pa}$. The deposition process consisted of three steps. First, the NBR substrates were etched by Ar plasma (300 sccm, $-900 \mathrm{~V}, 15 \mathrm{~min}$, and $5.8 \mathrm{~Pa}$ working pressure) to further remove surface contaminants. Second, oxygen $\left(\mathrm{O}_{2}\right)$, hydrogen $\left(\mathrm{H}_{2}\right)$, nitrogen $\left(\mathrm{N}_{2}\right)$, or $\mathrm{Ar}$ plasma were applied to improve the adhesion. In this step, the etching parameters $(100 \mathrm{sccm},-900 \mathrm{~V}$, $15 \mathrm{~min}$, and $5 \mathrm{~Pa}$ working pressure controlled by throttle) were constantly maintained. Finally, the DLC films were deposited with the following parameters: applied dc-negative bias power voltage of $-800 \mathrm{~V}$, frequency of $60 \mathrm{kHz}$, duty cycle of $60 \%$, and duration time of $120 \mathrm{~min}$. The gas flowrate was set to $\mathrm{Ar} / \mathrm{CH}_{4}=15 / 10 \mathrm{sccm}$, and the deposition pressure was kept constant at $20 \mathrm{~Pa}$. The obtained samples were named as Ar-X/DLC, where $X$ refer to the plasma treatment type in the second step. The pretreatment and deposition temperatures were strictly maintained at values below the upper limit $\left(150{ }^{\circ} \mathrm{C}\right)$ of NBR with a water cooling system, and the temperature fluctuation was measured with a surface thermometer.

\subsection{Sample characterization}

The morphology (surface and cross-sectional) of DLC/rubber was characterized by using a scanning electron microscope (ThermoScientific ${ }^{\mathrm{TM}}$ Apreo S, SEM). The cross sections of DLC/rubber were made by fracturing the specimens after cooling in liquid nitrogen for $10 \mathrm{~min}$. The cross-sectional profile was analyzed by using a 3D surface profilometer (ZYGO Nexview, USA). Raman spectra were acquired to investigate the chemical bonding of the DLC films by using a HORIBA Jobin Yvon S.A.S spectrometer at an excitation wavelength of the $532 \mathrm{~nm}$ Ar laser line and with a spot size of $5 \mu \mathrm{m}$. The integration time was $20 \mathrm{~s}$, and 3 accumulations were collected. The chemical state of the plasma-treated NBR samples was characterized by Fourier transform infrared spectroscopy (FTIR, Nexus 870) and X-ray photoelectron spectroscopy (XPS, PHI-570) with $\mathrm{Al} \mathrm{K} \alpha$ radiation as the excitation source.

In order to reliably determine the adhesion of DLC/rubber, the X-cut method was used to evaluate the adhesion levels. An " $X$ " was cut into DLC/rubber with a blade, in which the angle of the two crossed lines was approximately 30-45 degrees. A cellophane adhesive tape (Scotch ${ }^{\circledR}$ with adhesion to steel of $47 \mathrm{~N} / 100 \mathrm{~mm}$ widths) was carefully adhered to the dissected film surface under a $10 \mathrm{~N}$ load. After $2 \mathrm{~min}$, the tape was pulled off rapidly (not jerked). The peeling off or delamination of the film at X-cut area was observed by SEM [28]. The adhesion levels of DLC/rubber were quantitatively assessed by using a scratch tester, in which GCr15 steel balls ( $\varnothing 6 \mathrm{~mm}$ ) were used as counterparts. The test method was determined to be suitable for hard coating/soft substrate materials by Kaczorowski and Gajewski [29]. The scratch tester was an MFT-4000 multi-functional tester for material surface properties, which was manufactured by Lanzhou Huahui Instrument Technology Co. Ltd. (Lanzhou, China). The applied force linearly increased from 5 to $100 \mathrm{~N}$ over a distance of $10 \mathrm{~mm}$. The magnitude of the adhesion strength was comprehensively determined based on the SEM images and acoustic sign.

The friction performance of DLC/rubber was determined at room temperature $\left(23{ }^{\circ} \mathrm{C}\right)$ using an in-house tribo-tester with the rotating ball-on-disc configuration and commercial $ø 6 \mathrm{~mm}$ GCr15 steel balls as counterparts. The parameters of the friction tests were as follows: the friction load was $10 \mathrm{~N}$, the linear speed was $83.73 \mathrm{~mm} / \mathrm{s}$, the radius of rotation was $4 \mathrm{~mm}$, the testing time was $60 \mathrm{~min}$, and the relative humidity was maintained at $25 \% \pm 1 \%$ with a humidity regulator. All the 
tribo-tests were carried out at least three times to ensure repeatability.

\section{Results and discussion}

\subsection{Surface morphology of virgin and pretreated NBR}

Figure 1 shows the SEM micrographs of NBR without and with different plasma pretreatment. The surface of virgin NBR (after cleaning by soapy water and then boiling water) was covered by a smooth layer, as shown in Fig. 1(a), indicating that an aqueous soap solution is insufficient in removing wax and contaminants. Therefore, in the early stage of the treatment process, Ar plasma was chosen to remove the contaminants (at the molecule level) on the NBR surface, and decrease the influence of impurities on the subsequent plasma treatment. Pitted areas and holes with diameters of $200 \mathrm{~nm}$ were found on the NBR surface after $15 \mathrm{~min}$ of Ar plasma cleaning (Fig. 1(b)), indicating that Ar plasma can remove the adherent layer and strip the virgin rubber "skin". It should be noted that the role of Ar plasma is to transfer energy from the plasma towards the rubber surface (bombardment effect), and there is no chemical reaction between the Ar plasma and NBR [14]. In addition, the thermal effect caused by 15 min of Ar plasma discharge is negligible as the temperature only reaches $43{ }^{\circ} \mathrm{C}$.

The plasma in the second treatment stage has a significant effect on the morphology of the NBR surface (Figs. 1(c)-1(f)). Evidently, the rubber surface is degraded after the $\mathrm{O}_{2}$ plasma treatment (Fig. 1(c)). In contrast to the Ar plasma, the radicals in the $\mathrm{O}_{2}$ plasma may react with the additives and molecular chains of rubber [21]. Both chemical reactions and etching can accelerate the deterioration of the NBR surface and promote the formation of vertical spikes and fine voids on the surface. Compared with the $\mathrm{Ar}-\mathrm{O}_{2}$ plasma treatment, the damage to the rubber surface by the $\mathrm{Ar}-\mathrm{H}_{2}$ plasma is slighter. A rounded scaly sheet and homogeneous dispersion of holes of $50 \mathrm{~nm}$ in diameter are presented (Fig. 1(d)). An interesting phenomenon is the occurrence of bright particles grafted on the scaly sheet (Fig. 1(d)), which may be attributed to the chemical reactions involving the positive ions of the hydrogen plasma and the free radicals and chain molecules of the rubber surface [19]. In the case of Ar- $\mathrm{N}_{2}$ plasma treatments, a fine globular texture was observed on the NBR surface (Fig. 1(e)), attributable to the scission of rubber chains by the nitrogen plasma to increase the surface crosslinking of short chains. NBR treated with the Ar-Ar plasma resulted in a relatively homogeneous and smooth surface (Fig. 1(f)). As the Ar plasma treatment time increased (compared to Fig. 1(b)), the loose nanostructure changed to a
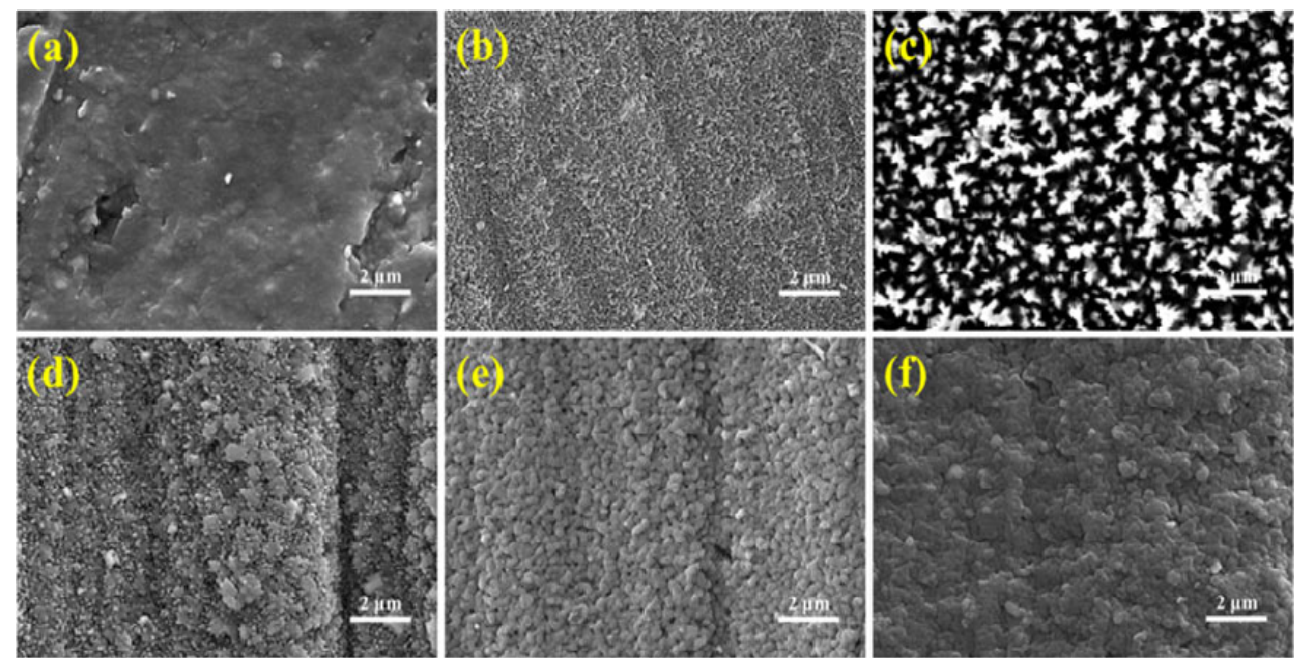

Fig. 1 Surface morphologies of NBR with different plasma pretreatments: (a) no pretreatment, (b) Ar plasma cleaning for 15 min, (c) $\mathrm{Ar}-\mathrm{O}_{2}$, (d) $\mathrm{Ar}-\mathrm{H}_{2}$, (e) $\mathrm{Ar}-\mathrm{N}_{2}$, and (f) $\mathrm{Ar}-\mathrm{Ar}$. 
compact configuration, which may be attributed to the transfer of energy from the Ar plasma to the NBR surface, thereby promoting the formation of free radicals and atomic migration [30]. From the SEM results, it can be inferred that oxidation reactions are initiated from the NBR surface under $\mathrm{O}_{2}$ plasma conditions. Furthermore, Ar plasma can promote the formation of free radicals at or near the NBR surface, which can convert lowmolecular-weight residues to high-molecularweight residues by crosslinking reactions.

\subsection{Composition and structure of virgin and pretreated NBR}

The chemical structures of the virgin and plasmatreated surfaces were characterized by FTIR spectroscopy. As shown in Fig. 2, there are three characteristic peaks at 2,917, 2,848, and $1,438 \mathrm{~cm}^{-1}$, corresponding to the $-\mathrm{CH}_{2}-$ nonsymmetry stretch vibration, $-\mathrm{CH}_{2}-$ symmetry stretch vibration, and $-\mathrm{CH}_{2}-$ non-symmetry changing angle vibration, respectively. It is known that the wax used in rubber manufacturing mainly contains these groups [31]. After the samples were treated with different plasma, the peak intensity of these groups in the FTIR spectra remarkably decreased, when compared with that of virgin NBR. The result confirms that plasma treatment can remove wax from the NBR surface, especially with Ar plasma and $\mathrm{O}_{2}$ plasma treatments. Furthermore,

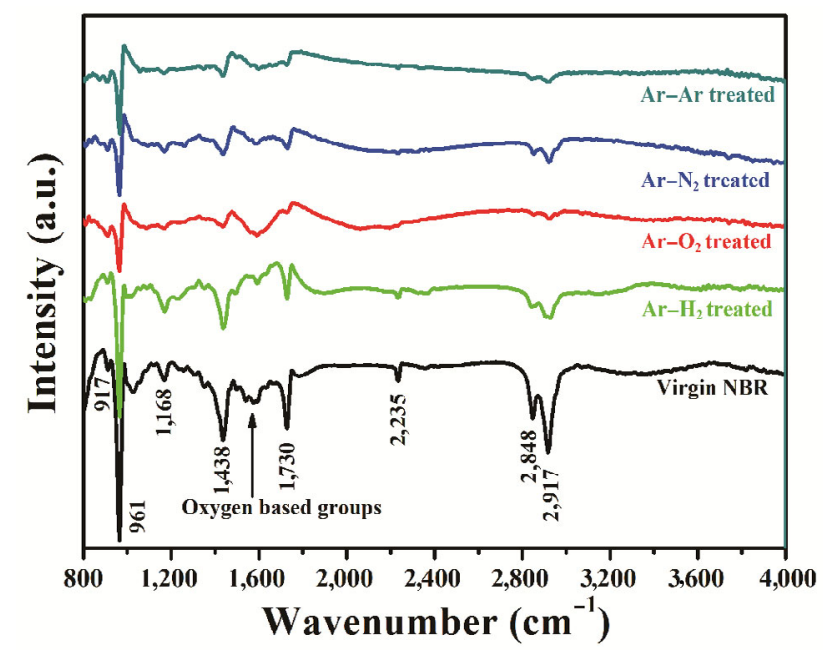

Fig. 2 FTIR spectra of NBR rubber before and after the different plasma treatments. the peaks at 2,235, 1,168, 961, and $917 \mathrm{~cm}^{-1}$ were respectively assigned to the $\mathrm{C} \equiv \mathrm{N}$ expansion vibration of unsaturated nitrile, $\mathrm{C}-\mathrm{H}$ in plane stretching vibration, the $\mathrm{C}-\mathrm{H}$ deformed vibration of two substituted alkenes, and the $\mathrm{C}-\mathrm{H}$ deformation vibration of mono substituted alkenes, representing the typical characteristic peaks of NBR [31]. Clearly, the Ar- $\mathrm{H}_{2}$ plasma-treated NBR surface displays the strongest intensities for the above peaks, indicating that this surface contains the greatest number of $\mathrm{C}-\mathrm{H}$ bonds.

Further, it was found that significant changes in the spectra occurred at $1,500-1,747 \mathrm{~cm}^{-1}$, which contains the $\mathrm{C}=\mathrm{O}$ stretch absorption at $1,730 \mathrm{~cm}^{-1}$ and the COO- asymmetrical stretch absorption at $1,650-1,560 \mathrm{~cm}^{-1}$ [10]. It can be seen that, except for the oxygen plasma-treated NBR, the intensities of the oxygen-based vibration peaks of the $\mathrm{Ar}, \mathrm{N}_{2}$, and $\mathrm{H}_{2}$ plasma-treated NBR are lower than that of the virgin NBR. In addition, according to Fig. 1(c) and the peaks in the spectral range of $1,650-1,560 \mathrm{~cm}^{-1}$ (Fig. 2), it is likely that two processes simultaneously occur during the oxygen plasma treatment: the formation of oxygencontaining functional groups on the NBR surface and the generation of volatile products. Overall, the recorded FTIR spectra for all the samples do not reveal any significant differences, except in the narrow spectral range of $1,650-1,560 \mathrm{~cm}^{-1}$. It is reasonable to conclude that modifications occur during cleaning and plasma irradiation, which resulted in the formation of free radicals and subsequent crosslinking.

To more accurately determine the chemical composition of the NBR rubber after plasma modification, XPS studies were performed. Figure 3 shows the XPS survey scan spectra of NBR before and after different plasma treatments. It is evident that the spectra consist peaks arising from carbon $(\mathrm{C} 1 \mathrm{~s})$, nitrogen $(\mathrm{N} 1 \mathrm{~s})$, and oxygen (O1s) at 284, 396.5, and $532 \mathrm{eV}$, respectively. In addition, weak peaks due to zinc $(\mathrm{Zn} 2 \mathrm{p})$ were observed, which is in good agreement with the composition of NBR. The oxygen contents $(\mathrm{O} / \mathrm{C}$ ratios) of the plasma-treated NBR is higher than that of the virgin NBR, which can be ascribed to 
the formation of oxygen-containing functional groups via the reaction of carbon radicals with oxygen molecules $\left(\mathrm{O}_{2}\right.$ and $\left.\mathrm{H}_{2} \mathrm{O}\right)$ when the samples are exposed to ambient air [32]. The different oxygen content may be used to qualitatively indicate the number of carbon radicals on the NBR surface resulting from the different plasma pretreatment. However, the increase in oxygen content upon oxygen plasma exposure is mainly attributed to the reaction of the $\mathrm{O}_{2}$ plasma with NBR. Another peculiar phenomenon is that an extremely small quantity of nitrogen (low N/C ratios) was incorporated on the NBR surface during the $\mathrm{N}_{2}$ discharge period. We believe that the affinity between the nitrogen-containing species and carbon radicals on the NBR surface is low (Fig. 3), and that low oxygen contamination may strongly hamper the incorporation of nitrogen on the NBR surface.

Considering that the adhesion between the DLC films and NBR substrates is dependent on the chemical structure of the NBR surface, the two regions of the spectrum, namely $\mathrm{C} 1 \mathrm{~s}$ and $\mathrm{O} 1 \mathrm{~s}$, were further subjected to detailed analysis. Figures S1 and S2 in the Electronic Supplementary Material (ESM) show the high-resolution XPS spectra in the $\mathrm{C} 1 \mathrm{~s}$ and O1s regions of NBR before and after different plasma treatments. The $\mathrm{C} 1$ s spectrum can be fitted to three components corresponding to $\mathrm{C}-\mathrm{C} / \mathrm{C}-\mathrm{H}(284.8 \mathrm{eV}), \mathrm{C}-\mathrm{N} / \mathrm{C}-\mathrm{O}(285.8 \mathrm{eV})$, and $\mathrm{O}=\mathrm{C}-$

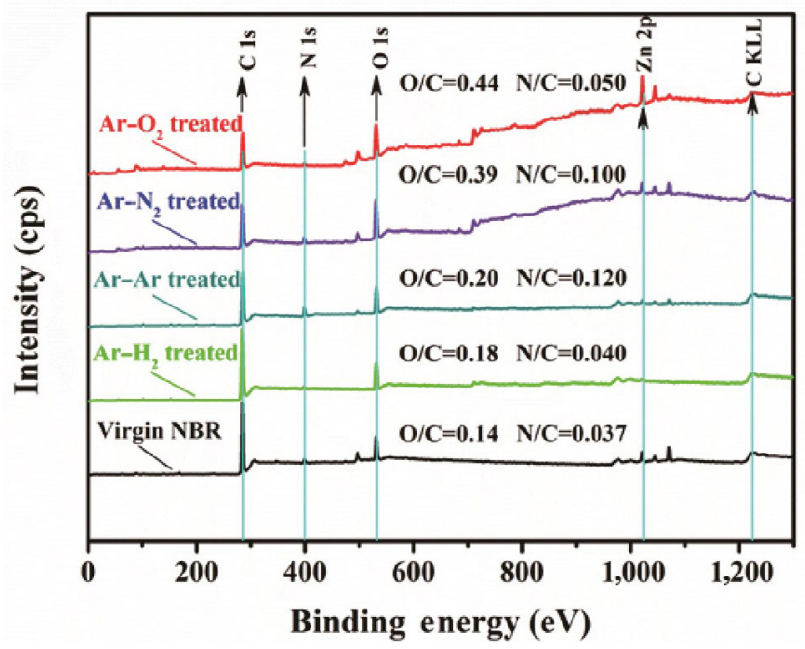

Fig. 3 XPS wide scan spectra of NBR rubber before and after the different plasma treatments.
$\mathrm{O} / \mathrm{O}=\mathrm{C}-\mathrm{N}(288.3 \mathrm{eV})$, respectively. The proportion of the $\mathrm{C}-\mathrm{C} / \mathrm{C}-\mathrm{H}$ component is significant and most likely originated from the hydrocarbon backbone of NBR [30]. $\mathrm{H}_{2}$ plasma was found to promote the increase in the $\mathrm{C}-\mathrm{C}$ and $\mathrm{C}-\mathrm{H}$ bonds, which can be attributed to the incorporation of hydrogen atoms on the NBR surface (Fig. S1 in the ESM). Moreover, an evident change in the ratio of the $\mathrm{C}-\mathrm{N} / \mathrm{C}-\mathrm{O}$ and $\mathrm{O}=\mathrm{C}-\mathrm{O} / \mathrm{O}=\mathrm{C}-\mathrm{N}$ peak was observed, where the ratios for the different plasma-treated NBRs are greater than that of virgin NBR (Fig. S1 in the ESM). Notably, the ratio of $\mathrm{C}-\mathrm{N} / \mathrm{C}-\mathrm{O}$ is the highest in the NBR treated with the Ar-Ar plasma (Fig. S1 in the ESM), which indicates that Ar plasma is the most effective at subtracting hydrogen and forming carbon free radicals at or near NBR surface, thus facilitating the deposition of DLC films.

The deconvolution of the O1s band (Fig. S2 in the ESM) revealed three peaks, which were assigned to $\mathrm{C}-\mathrm{O}-\mathrm{C} \quad(533.2 \mathrm{eV}), \quad \mathrm{C}-\mathrm{OH} / \mathrm{C}=\mathrm{O}$ $(532.2 \mathrm{eV})$, and $\mathrm{Zn}-\mathrm{O} / \mathrm{O}=\mathrm{S}=\mathrm{O}(530.6 \mathrm{eV})$. For all the plasma-treated samples, the $\mathrm{Zn}-\mathrm{O} / \mathrm{O}=\mathrm{S}=\mathrm{O}$ peak exhibited the most significant change when compared with that of virgin NBR (Fig. S2 in the ESM). This suggests that plasma treatment is effective at removing the sticky layer on the NBR surface. Meanwhile, plasma modification also acts to expose a large amount of fillers from the bulk to the rubber surface, which may have an adverse effect on the deposition of DLC films deposition. Therefore, according to the area of the $\mathrm{Zn}-\mathrm{O} / \mathrm{O}=\mathrm{S}=\mathrm{O}$ peak, more fillers are exposed on the NBR surfaces treated with oxygen and nitrogen plasma (Fig. S2 in the ESM).

\subsection{Surface morphology of DLC/rubber}

The surface morphologies of the DLC/rubber specimens are shown in Fig. 4. As can be seen from the low-magnification images, the stripe-like and uneven granular morphology is remarkable in Ar- $\mathrm{O}_{2} /$ DLC (Fig. 4(a)). By contrast, stripe-like and patch-like morphologies were observed for the other DLC/rubber specimens (Figs. 4(c) and 4(d)). The stripe-like morphology is attributed to the injection molding used in the NBR manufacturing process. The patch-like morphology is a typical 

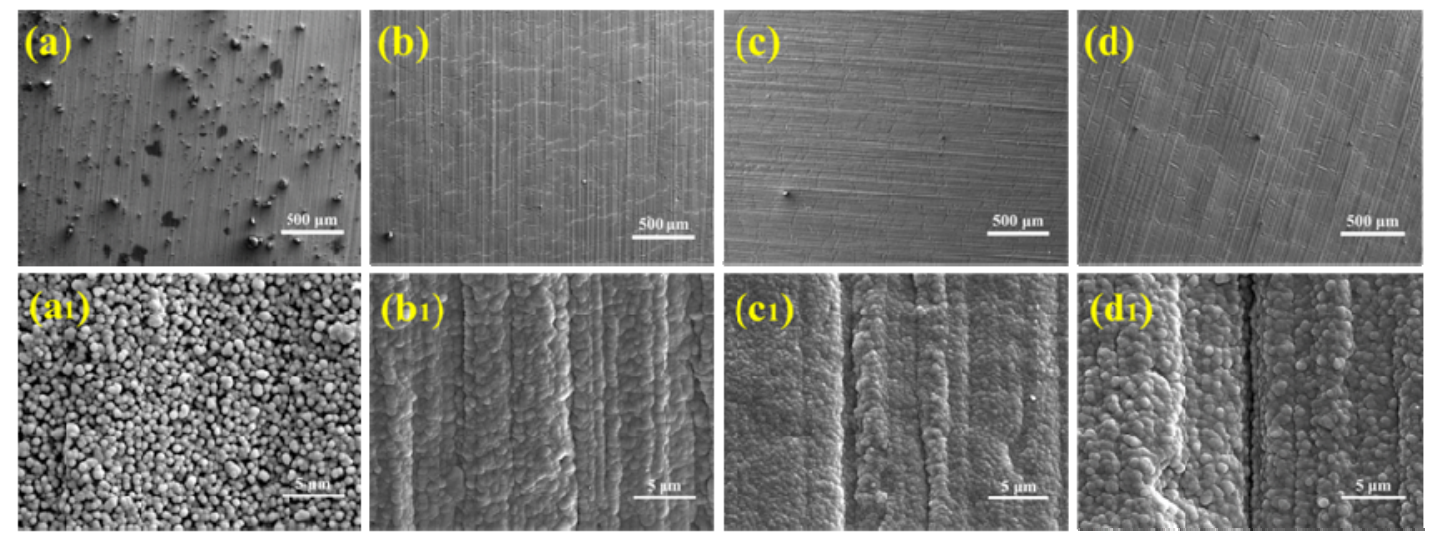

Fig. 4 Microstructure of DLC/rubber with different plasma pretreatments: (a) $\mathrm{Ar}-\mathrm{O}_{2}$, (b) $\mathrm{Ar}-\mathrm{H}_{2}$, (c) $\mathrm{Ar}-\mathrm{N}_{2}$, and (d) $\mathrm{Ar}-\mathrm{Ar}$. Top: lower magnification (scale bar: $500 \mu \mathrm{m}$ ); bottom: higher magnification (scale bar: $5 \mu \mathrm{m}$ ).

feature of hard coatings deposited on soft or flexible substrates, which is induced by the huge difference in the thermal expansion coefficient and elasticity between the DLC films and NBR substrates. However, it can be seen that the surface of $\mathrm{Ar}-\mathrm{O}_{2} / \mathrm{DLC}$ contains a few cracks, attributable to the formation of voids on NBR after the $\mathrm{Ar}-\mathrm{O}_{2}$ plasma treatment (Fig. 1(c)). Furthermore, the density of the crack network is similar for DLC/ rubber with $\mathrm{Ar}-\mathrm{N}_{2}, \mathrm{Ar}-\mathrm{H}_{2}$, and $\mathrm{Ar}-\mathrm{Ar}$ plasma pretreatments (Figs. 4(b) $-4(\mathrm{~d})$ ). Consequently, the effect of the crack network density on the adhesion and friction performance of DLC/rubber is negligible in the follow-up discussion.

At high magnification, it can be seen that the Ar- $\mathrm{O}_{2} / \mathrm{DLC}$ film has the loosest and grainiest morphology (Fig. 4(a1)). It is likely that the vertical spikes and fine voids on the surface of the NBR with the $\mathrm{Ar}-\mathrm{O}_{2}$ plasma treatment greatly influence the nucleation and impingement of carbon atoms during the deposition of DLC films (Fig. 1(c)). The DLC films prepared on the other plasma-treated NBR surfaces are relatively compact (Figs. $\left.4\left(b_{1}\right)-4\left(d_{1}\right)\right)$ with a network of grooves, where the micron valley structure may store debris during friction. Notably, the uneven granular structure divided by a gap of tens of nanometers is expected to enhance the strain tolerance and flexibility of $\mathrm{Ar}-\mathrm{O}_{2} / \mathrm{DLC}$. However, the DLC films may not protect the NBR matrix, because the NBR substrates can directly contact external impurities via the gap.

\subsection{Cross-sectional profile analysis}

The fractured cross-sections of DLC/rubber are shown in Fig. 5. The fractured cross-sectional morphology of $\mathrm{Ar}-\mathrm{O}_{2} / \mathrm{DLC}$ contains a loose and columnar microstructure (Fig. 5(a)), which may be related to the voids on the NBR surface (Fig. 1(c)) hindering the continuous growth of DLC films. In the case of $\mathrm{Ar}-\mathrm{H}_{2} / \mathrm{DLC}$, the fractured crosssectional morphology clearly reveals the formation of defects. Although it is common that numerous $\mathrm{C}-\mathrm{H}$ bonds are formed by passivation, adhesion can be improved by dehydrogenation during film deposition [15]. However, these interface holes indicate that this was not achieved (Fig. 5(b)), which can be explained by the ocean of $\mathrm{H}$ ions on
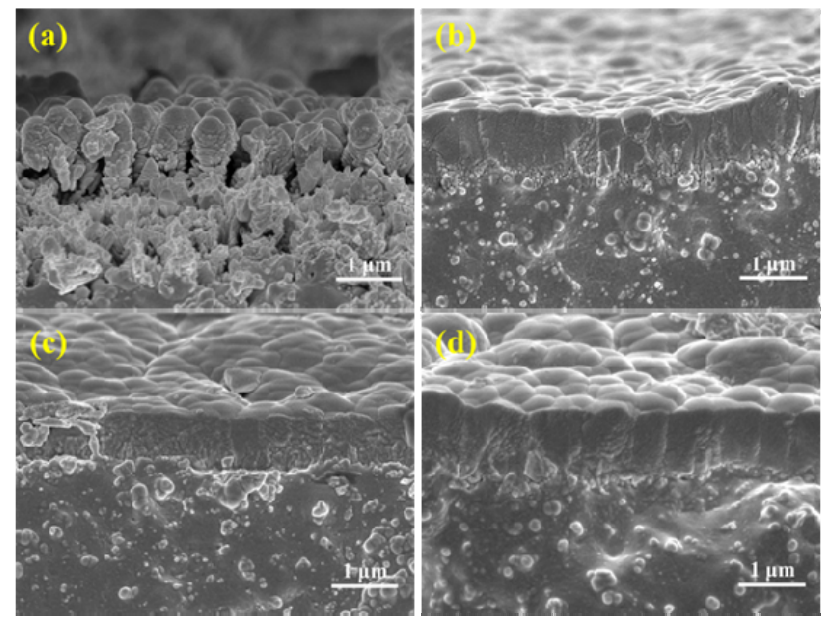

Fig. 5 Fracture cross-sections of DLC/rubber with different plasma pretreatments: (a) $\mathrm{Ar}-\mathrm{O}_{2}$, (b) $\mathrm{Ar}-\mathrm{H}_{2}$, (c) $\mathrm{Ar}-\mathrm{N}_{2}$, and (d) Ar-Ar. 
the rubber surface at the beginning of the deposition process (Fig. S1 in the ESM), hindering dehydro-genation for a short time and thus holes are formed via bridges. In the case of $\mathrm{Ar}-\mathrm{N}_{2} / \mathrm{DLC}$ and $\mathrm{Ar}-\mathrm{Ar} / \mathrm{DLC}$, the interface between the DLC films and rubber is compact, which can be correlated to the free radicals and surface topography after plasma pretreatment (Figs. 5 (b) and 5(d)).

A section analysis is conducted by drawing a cross-sectional line across the pretreated rubber and DLC/rubber surface, as shown in Fig. 6. The roughness value of the NBR with the $\mathrm{Ar}-\mathrm{O}_{2}$ plasma pretreatment is higher than that of the virgin rubber surface, whereas the roughness values of the NBR with the other plasma pretreatments are lower than that of the virgin rubber surface (Fig. 6(a)). This can be attributed to the large number of voids formed on the rubber surface after the oxygen plasma pretreatment (Fig. 1(c)), while the other plasmas removed impurities and promoted crosslinking for a smoother rubber surface. Compared with the roughness of the plasma-pretreated rubber, the surface roughness of the corresponding DLC/rubber is reduced. This can be explained by the shadowing model of columnar growth, which is initiated from the rough surface where carbon atoms are accumulated in the holes embedded in the rubber surface [19]. In particular, it should be noted that the amplitude of the cross-sectional profile of Ar-Ar/DLC is significantly enhanced when compared with the Ar-Ar plasma-treated rubber surface profile, but the average roughness is relatively low (Fig. 6). From the section analysis (Fig. 6(a)), the Ar-Ar plasma-treated rubber surface is smooth and the distribution of fine holes is relatively uniform. According to the shadowing model of columnar growth, free radical carbon atoms will firstly accumulate in the holes to facilitate the formation of columnar structures [19]. A closer examination of the results indicates that the average roughness is almost the same for Ar-Ar/DLC, Ar- $\mathrm{N}_{2} / \mathrm{DLC}$, and Ar- $\mathrm{H}_{2} / \mathrm{DLC}$, whereas the vibration intensity of the cross-section line shows the following order: $\mathrm{Ar}-\mathrm{Ar} / \mathrm{DLC}>\mathrm{Ar}-\mathrm{N}_{2} /$ DLC $>$ Ar- $\mathrm{H}_{2} /$ DLC (Fig. 6(b)). It must be pointed out that the fluctuations, presenting an approximate sine function for Ar-Ar/DLC, have a huge impact on the friction performance of the sample, which will be mentioned later. Notably, the cross-sectional profile of $\mathrm{Ar}-\mathrm{O}_{2} / \mathrm{DLC}$ deviates from the morphology of the fractured cross section (Fig. 5(a)), which can be attributed to the scanning range and accuracy of the measurement. The scanning range in Fig. 5(a) is only $6 \mu \mathrm{m}$, while the scanning range of the threedimensional profile is $1.0 \mathrm{~mm}$ (Fig. 6(b)). Therefore, the columnar structure surfaces are not reflected in the optical 3 dimentional (3D) surface profilometry due to the nanoscale voids. Further, we provide a small range $(0.1 \mathrm{~mm})$ of the cross-sectional profile (Fig. S3 in the ESM), and find that the profile curve is closer to the topography of $\mathrm{Ar}-\mathrm{O}_{2} / \mathrm{DLC}$ (Fig. 5(a)).
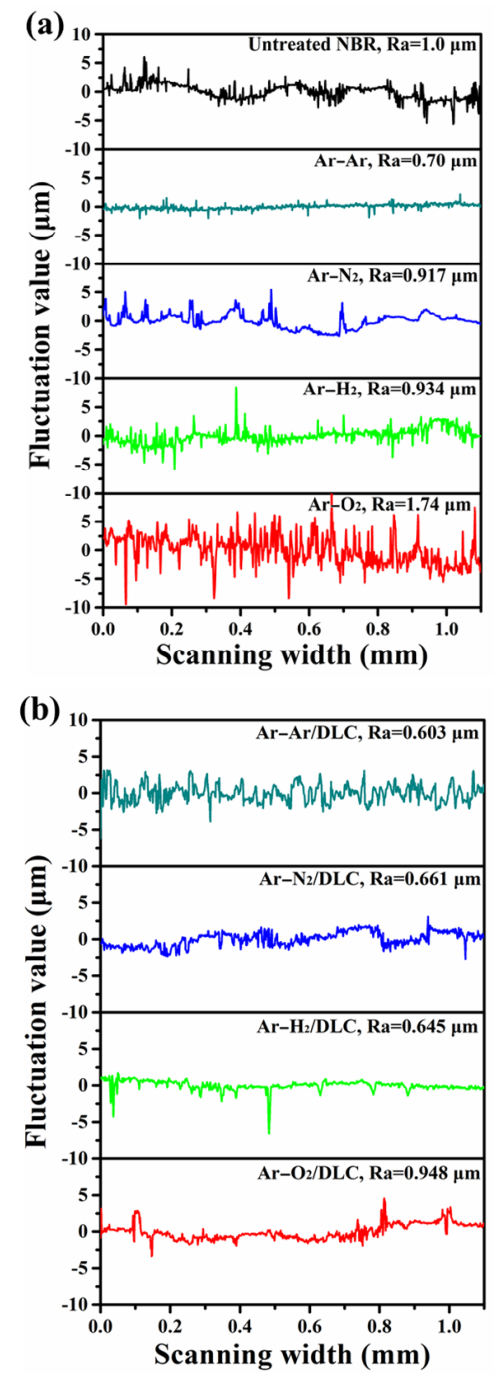

Fig. 6 Cross-sectional profile of (a) untreated and plasma-treated NBR and (b) DLC/rubber with different plasma pretreatment. 


\subsection{Raman analysis of DLC/rubber}

Raman spectroscopy is an effective and nondestructive tool to characterize the detailed bonding structure of DLC films. The full spectra of DLC/rubber with various plasma pretreatments are shown in Fig. 7(a), consisting of the prominent $G$ and smaller underlying $D$ peaks (centered approximately 1,530 and $1,350 \mathrm{~cm}^{-1}$, respectively). The G-peak is attributed to the stretching vibration of the $\mathrm{sp}^{2}$ bonds in chains or in aromatic rings, and the D-peak is assigned to the breathing mode of the $\mathrm{sp}^{2}$ bonds in the rings only [33, 34]. Generally, more information on the carbon bonds can be derived by the deconvoluted data including the G-peak position and the intensity ratio of the $\mathrm{D}$ to $\mathrm{G}$ peaks $\left(I_{\mathrm{D}} / \mathrm{I}_{\mathrm{G}}\right)$, where the $\mathrm{G}$-peak position is considered to depend on the $\mathrm{sp}^{2}$ content and the $I_{\mathrm{D}} / I_{\mathrm{G}}$ ratio has a direct correlation with the $\mathrm{sp}^{2} / \mathrm{sp}^{3}$ ratio.

The variation of the fitted G-peak position and $I_{\mathrm{D}} / I_{\mathrm{G}}$ values of DLC on the various plasmapretreated NBR are depicted in Fig. 7(b). There is no obvious change in the $G$ peak position $\left(1,527 \pm 2 \mathrm{~cm}^{-1}\right)$ and $I_{\mathrm{D}} / I_{\mathrm{G}}$ ratio $(0.44 \pm 0.03)$ for $\mathrm{Ar}-\mathrm{N}_{2} / \mathrm{DLC}$, Ar- $\mathrm{H}_{2} / \mathrm{DLC}$, and $\mathrm{Ar}-\mathrm{Ar} / \mathrm{DLC}$, which suggests that the microstructure of the DLC films was not influenced by the $\mathrm{N}_{2}, \mathrm{H}_{2}$, and Ar plasma pretreatments. However, the G-peak position and $I_{\mathrm{D}} / I_{\mathrm{G}}$ ratio of $\mathrm{Ar}-\mathrm{O}_{2} / \mathrm{DLC}$ are higher than those of the other samples. This may be attributed to the growth of the film in irregular patterns, increasing the $\mathrm{sp}^{2}$ content through carbon agglomeration [35]. The granular surface topography of the $\mathrm{Ar}-\mathrm{O}_{2}$ plasma-treated rubber results in a decrease in diffusivity of carbon on the rubber surface, which further leads to the formation of $\mathrm{sp}^{2}$-bonds by carbon agglomeration. Moreover, the irregular coating may be attributed to the poor bonding between the NBR substrates and carbon particles due to the limited activation sites. The poor bonding may lead to an increased affinity between the carbon-carbon particles during the deposition process, increasing the $\mathrm{sp}^{2}$ bond content. Therefore, the results confirm that the type of plasma pretreatment has little effect on the microstructure (a)
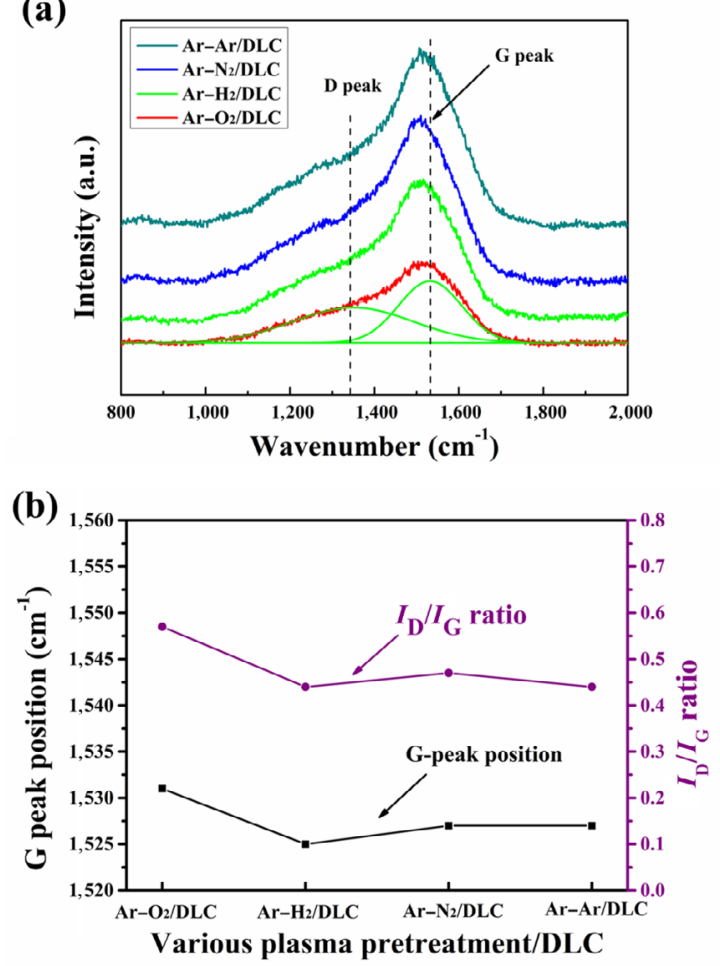

Fig. 7 (a) Raman spectra and (b) $I_{\mathrm{D}} / I_{\mathrm{G}}$ and $\mathrm{G}$ peak position of DLC/rubber with various plasma pretreatments.

of the DLC films, although the surface topography of the rubber substrates is affected.

\subsection{Adhesion}

To examine the interfacial adhesion strength of DLC/rubber with different plasma pretreatments, the $\mathrm{X}$-cut method and scratch tests were performed. Figure 8 shows the SEM images of the $\mathrm{X}$-cuts after the peeling tests. Although adhesion cannot easily be assessed by the $X$-cut incision, the pattern on the adhesive tape of the X-cuts (upper right corner of each corresponding image) can be used to qualitatively distinguish the adhesion strength. Film peeling ccurs at the incision and edges on the $\mathrm{Ar}-\mathrm{O}_{2} / \mathrm{DLC}$ surface, and trace peelings appear in the incisions on the $\mathrm{Ar}-\mathrm{H}_{2} / \mathrm{DLC}$ surface (Figs. 8(a) and 8(b)). However, it is difficult to distinguish the adhesion strength of $\mathrm{Ar}-\mathrm{N}_{2} / \mathrm{DLC}$ and $\mathrm{Ar}-\mathrm{Ar} / \mathrm{DLC}$ because both display incisional marks. Moreover, the film at the edge of the incision is distinctly not attached to the tape (Figs. 8(c) and 8(d)). Evidently, the adhesion strengths of $\mathrm{Ar}-\mathrm{N}_{2} / \mathrm{DLC}$ and Ar-Ar/DLC are much higher than 
those of Ar-O $/$ DLC and Ar- $\mathrm{H}_{2} / \mathrm{DLC}$. Based on the above observations, it can be concluded that the choice of adhesive tape is particularly critical and the use of tape is limited in the determination of the adhesion strength. Therefore, the adhesion strength of the samples is further studied in the following tests.

Table 1 shows the scratch test data for DLC/rubber with different plasma pretreatment, where the surface image and acoustic sign obtained after the scratch tests are presented in Fig. S4 in the ESM. Two critical loads were determined: the lower critical load (Lc1) causes the film to tilt up and the upper critical load (Lc2) damages the DLC films from the NBR surface. The values of Lc1 and Lc2 are respectively 21.26 and $63.68 \mathrm{~N}$ for the Ar-Ar/DLC and 20.43 and $50.25 \mathrm{~N}$ for Ar- $\mathrm{N}_{2} /$ DLC. Therefore, the adhesion strengths of all the films can be arranged as follows: Ar-Ar/DLC > $\mathrm{Ar}-\mathrm{N}_{2} / \mathrm{DLC}>\mathrm{Ar}-\mathrm{H}_{2} / \mathrm{DLC}>\mathrm{Ar}-\mathrm{O}_{2} / \mathrm{DLC}$.

The adhesive strength is significantly affected by the plasma modification of the NBR substrates.

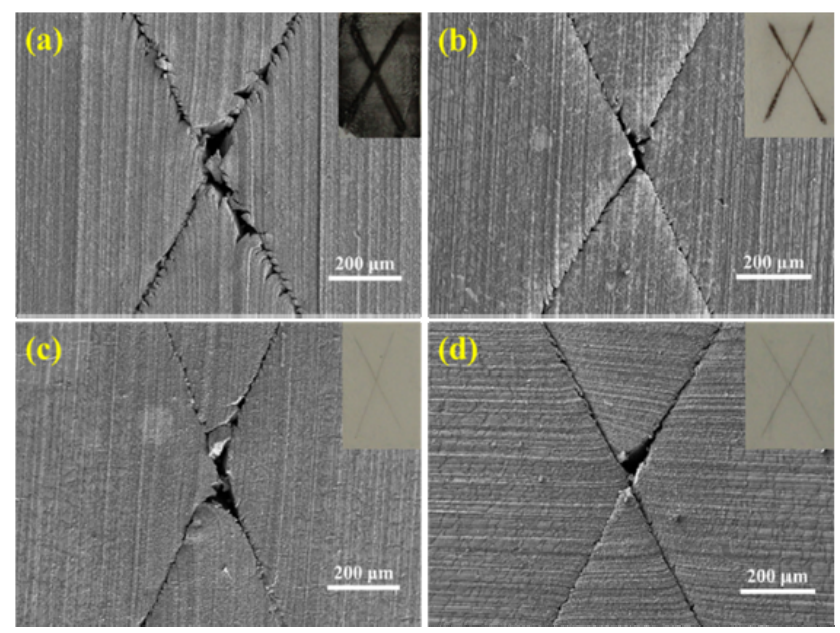

Fig. 8 SEM images of X-cuts after peel tests for DLC/rubber with different plasma pretreatments: (a) $\mathrm{Ar}-\mathrm{O}_{2}$, (b) $\mathrm{Ar}-\mathrm{H}_{2}$, (c) $\mathrm{Ar}-\mathrm{N}_{2}$, and (d) $\mathrm{Ar}-\mathrm{Ar}$.

Table 1 Comparison of the adhesion of DLC/rubber with different plasma pretreatments.

\begin{tabular}{lcc}
\hline DLC/rubber & Critical load Lc1 $(\mathrm{N})$ & Critical load Lc2 $(\mathrm{N})$ \\
\hline $\mathrm{Ar}-\mathrm{O}_{2} / \mathrm{DLC}$ & 5.14 & 12.87 \\
$\mathrm{Ar}-\mathrm{H}_{2} / \mathrm{DLC}$ & 12.60 & 24.30 \\
$\mathrm{Ar}-\mathrm{N}_{2} / \mathrm{DLC}$ & 18.43 & 50.25 \\
$\mathrm{Ar}-\mathrm{Ar} / \mathrm{DLC}$ & 21.26 & 63.68 \\
\hline
\end{tabular}

Although $\mathrm{O}_{2}$ plasma is capable of removing organic contaminants [36], it further reacts with the rubber matrix to deteriorate the rubber surface, i.e., creating a surface morphology of vertical spikes and fine voids (Fig. 1(c)). This morphology prevents the DLC films from fully contacting the rubber, resulting in segmentation-like columnar growth of the DLC films and poor adhesion. Similarly, the $\mathrm{H}_{2}$ plasma pretreatment failed to enhance adhesion, even though the treatment was designed to promote the formation of $\mathrm{C}-\mathrm{H}$ bonds and induce dehydrogenation at the beginning of the film deposition to improve adhesion. However, dehydrogenation was not achieved in the short DLC deposition time, resulting in the formation of a large amount of voids at the interface between the DLC film and NBR substrate (Fig. 5(b)). The $\mathrm{N}_{2}$ plasma was not as effective as the Ar plasma at improving adhesion, which can be attributed to the increased surface crosslinks between fragile short chains and the large amounts of fillers exposed on the rubber surface (Fig. S2 in the ESM). The Ar plasma treatment is the most effective at enhancing adhesion. Plasma based on noble gases (e.g., He or Ar) are effective at creating free radicals on the NBR surfaces. The free radicals produced by the Ar plasma can only link other surface radicals or other chains in chain-transfer reactions [37]. Therefore, it can be deduced that the increased adhesion strength of DLC/rubber is related to the removal of organic contamination and weak boundary layers, and the formation of free radicals.

To further investigate the relationship between adhesion and carbon free radicals, we measured the water contact angle to indirectly account for the changes in free radicals, because a greater free radical content produces a higher surface energy which is manifested in the formation of small water contact angles [38]. Figure 9 shows the optical image of a water droplet on the surfaces of virgin NBR and different plasma-pretreated NBR samples. The order of contact angle was found to show an opposite trend with adhesion strength, indicating that carbon free radicals play a key role in adhesion (Fig. 9). In addition, the contact angle 


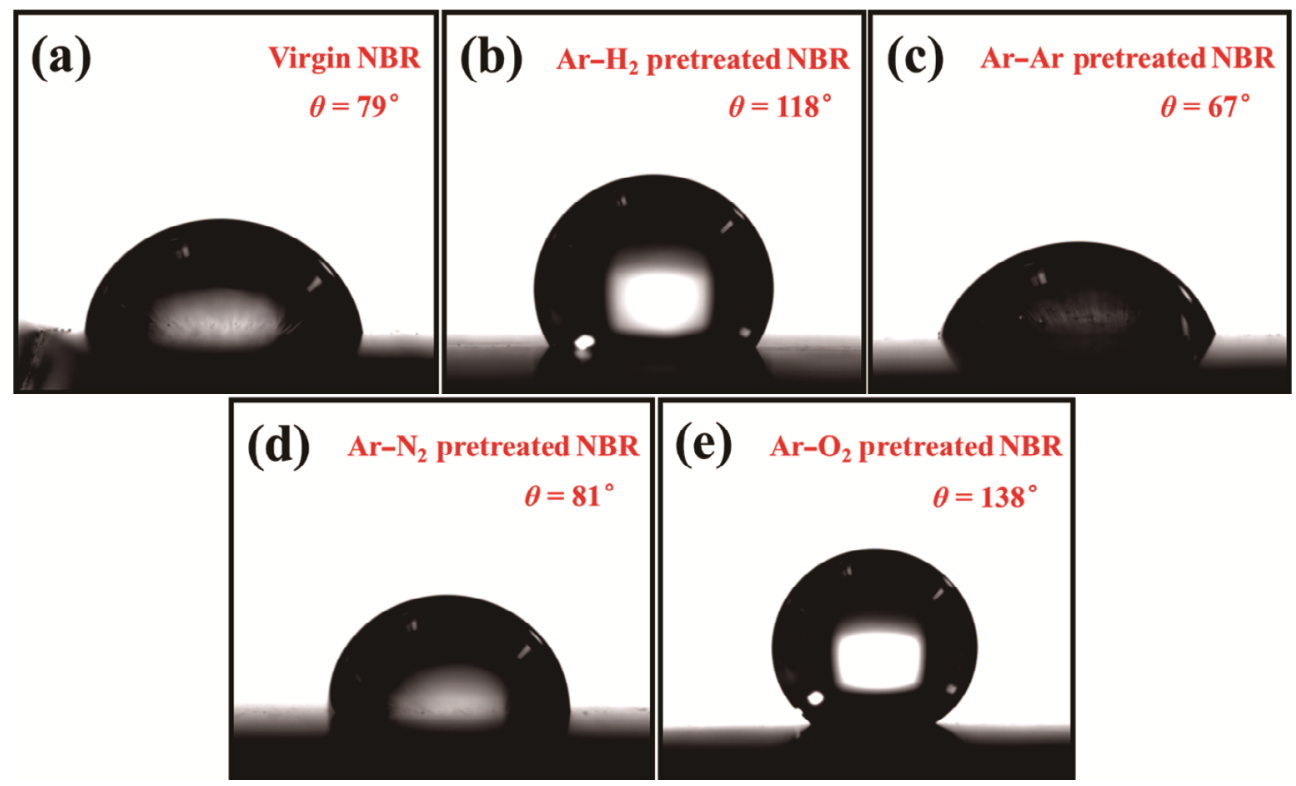

Fig. 9 Optical image of a water droplet on the surface of NBR. (a) Without pretreatment and with different plasma pretreatments: (b) $\mathrm{Ar}-\mathrm{H}_{2}$, (c) $\mathrm{Ar}-\mathrm{Ar}$, (d) $\mathrm{Ar}-\mathrm{N}_{2}$, and (e) $\mathrm{Ar}-\mathrm{O}_{2}$.

of NBR with water is greatly reduced after the Ar-Ar plasma treatment (Fig. 9(c)), indicating that the Ar plasma facilitates the generation of carbon free radicals, in agreement with the XPS results (Fig. S1). Notably, the wettability of rubber changed after the $\mathrm{O}_{2}$ plasma treatment, from a hydrophilic surface to a hydrophobic one, which may be attributed to the surface morphology of vertical spikes and fine voids.

\subsection{Friction performance}

The evolution of the friction coefficient $(\mathrm{CoF})$ as a function of the sliding cycles of virgin NBR and DLC/rubber with different plasma pretreatments is shown in Fig. 10. The deposition of DLC films significantly reduced the $\mathrm{CoF}$, attributable to the chemical inertness of the DLC films, which separates the rubber molecules from the counterparts. The friction curve of $\mathrm{Ar}-\mathrm{Ar} / \mathrm{DLC}$ achieved a steady state, whereas a continuous growth in $\mathrm{CoF}$ was observed for the other curves. The trend of the average CoF (Fig. 10 insert) is consistent with that for the adhesion of DLC/rubber with different plasma pretreatments. Therefore, excellent adhesion may ensure that DLC films exhibit stable performance in a sustained friction test. For $\mathrm{Ar}-\mathrm{O}_{2} / \mathrm{DLC}$, the initial
CoF was as low as 0.20 and instability increased with the sliding time (Fig. 10). By the end of the test, the CoF reached a relatively high value of 0.52 . The instability in the friction curve together with the gradual increase in the $\mathrm{CoF}$ indicates a gradual damage of the DLC films. In addition to the poor adhesion, the deteriorating mechanical strengths of the rubber surface and DLC films contribute to the poor friction performance of $\mathrm{Ar}-\mathrm{O}_{2} / \mathrm{DLC}$. The friction curves of $\mathrm{Ar}-\mathrm{H}_{2} / \mathrm{DLC}$ and $\mathrm{Ar}-\mathrm{N}_{2} / \mathrm{DLC}$ show an upward trend, indicating that the DLC films are still functional. This may be related to the viscoelastic characteristics of the plasma-pretreated rubber, resulting in variable sizes of the contact area between the counterpart ball and the DLC films. Notably, the higher slope of the friction curve growth of $\mathrm{Ar}-\mathrm{H}_{2} / \mathrm{DLC}$ is a direct result of poor adhesion, causing the edges of the sharp cracks to tilt up and exert additional resistance against the counterpart. The increase in $\mathrm{CoF}$ of the DLC/rubber with $\mathrm{N}_{2}$ plasma pretreatment may also be associated with the irregular surface profile of the DLC films. The Ar plasma pretreatment is the most effective at improving the friction properties of DLC/rubber. The friction curve with a slope of almost zero is an indicator that the film maintained steady state conditions and does not 


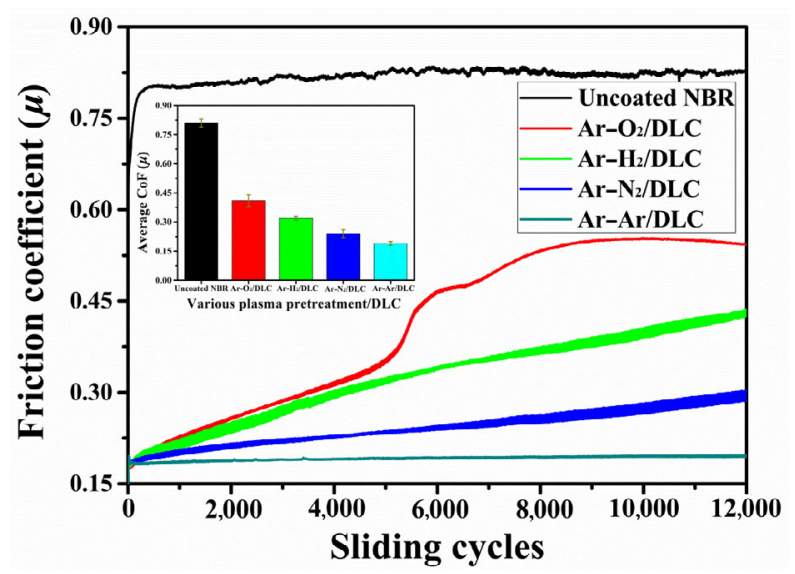

Fig. $10 \mathrm{CoF}$ of virgin NBR and DLC/rubber with different plasma pretreatments.

suffer much damage. The greatest friction performance was observed for Ar-Ar/DLC, which can be explained as follows: (1) The sharp banks of the cracks extend into the interior of the rubber due to the excellent adhesion (as shown in Fig. $\left.4\left(\mathrm{~d}_{1}\right)\right)$, which results in blunted banks and thus a decrease in the friction force. (2) The formation of concave ("valley") and convex ("hill") features on the Ar-Ar/DLC surface seems to have a positive influence on its frictional characteristics. The approximate sin function fluctuation mode (as shown in Fig. 6(b)) can reduce the contact area during the tribo-tests, which in turn reduces the adhesive contribution to friction, resulting in a stable CoF. (3) The Ar plasma pretreatment facilitates the formation of a compact layer on the rubber surface (Fig. 1(f)), and thus the NBR surface becomes stiffer and the viscoelastic contribution to friction is reduced. Therefore, the decrease in the adhesive interaction and hysteresis contribution lays a foundation for superior friction performance.

The wear tracks formed on DLC/rubber with different plasma pretreatments are illustrated in Fig. 11. The discrete columnar structures in $\mathrm{Ar}-\mathrm{O}_{2} / \mathrm{DLC}$ are seriously damaged after the tribo-tests, even though they appear to adhere to the substrate (Fig. 11(a)), indicating that the $\mathrm{O}_{2}$ plasma cannot enhance the adhesion of DLC/ rubber and the load bearing capability is weakened. In addition, the broken particles at the periphery of the patch-like structures are stored in

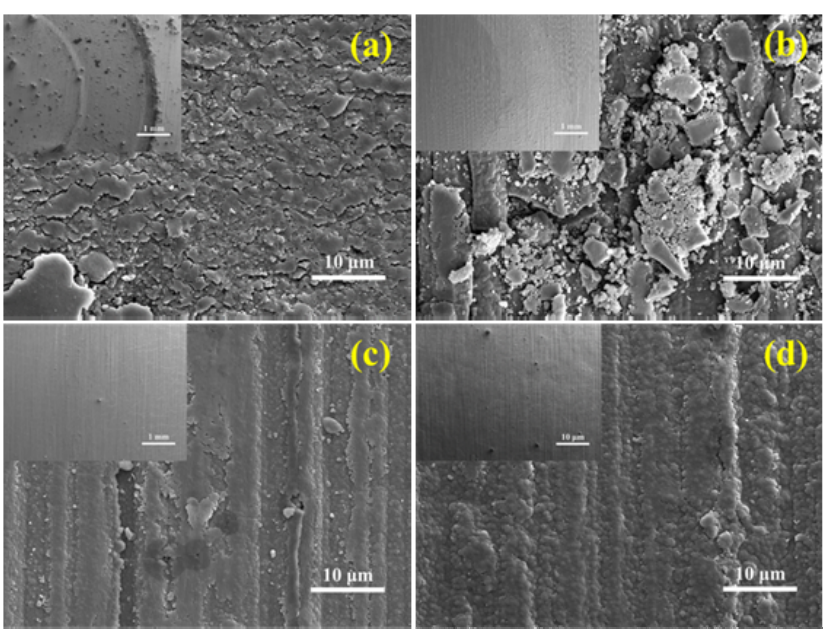

Fig. 11 Microscopic SEM images of the wear tracks of DLC/rubber with different plasma pretreatments: (a) $\mathrm{Ar}-\mathrm{O}_{2}$, (b) $\mathrm{Ar}-\mathrm{H}_{2}$, (c) $\mathrm{Ar}-\mathrm{N}_{2}$, and (d) $\mathrm{Ar}-\mathrm{Ar}$.

the wear tracks on $\mathrm{Ar}-\mathrm{H}_{2} / \mathrm{DLC}$ (Fig. 11(b)). The crack edges that are bent outwards are likely the main source of debris. However, the wear tracks of Ar- $\mathrm{N}_{2} / \mathrm{DLC}$ and Ar-Ar/DLC are hardly visible at low magnification (Figs. 11(c) insert and 11(d) insert). Closer observations reveal that some of the tiny smooth plates are abraded and polished by the counterparts. Therefore, the segmented structure and uneven films suppress the generation of wear particles, and the worn areas only occur at the top of the patches. The significant wear and the rise of $\mathrm{CoF}$ of $\mathrm{Ar}-\mathrm{N}_{2} / \mathrm{DLC}$, compared with $\mathrm{Ar}-\mathrm{Ar} / \mathrm{DLC}$, can be attributed to the irregular surface morphology of the DLC films and the granular surface structure on the $\mathrm{N}_{2}$ plasmapretreated NBR. In addition, the fine patch-like microstructure of the DLC films has been reported to impart DLC/rubber with excellent friction performance $[17,22]$. The sizes of the patches are almost identical in our samples, except for $\mathrm{Ar}-\mathrm{O}_{2} /$ DLC, and thus the effect of film flexibility on friction performance was not further considered.

\section{Conclusions}

The adhesion and friction performance of DLC/rubber with different plasma pretreatments were evaluated. Plasma treatments significantly affected the surface morphology and chemical property of the NBR surface. According to the 
FTIR and XPS results, Ar plasma and $\mathrm{O}_{2}$ plasma were proved to be effective at removing wax and contaminants on the rubber surface. However, $\mathrm{O}_{2}$ plasma can continue to react with the molecular chains of rubber, contributing to the decline in the surface mechanical properties, adhesion, and friction performance of DLC/rubber. The adhesion of $\mathrm{Ar}-\mathrm{H}_{2} / \mathrm{DLC}$ is relatively low, which is considered as the main reason for the rise in $\mathrm{CoF}$. The increase in $\mathrm{CoF}$ of $\mathrm{Ar}-\mathrm{N}_{2} / \mathrm{DLC}$ can be associated with the surface crosslinks between fragile short chains, the exposed fillers on the modified rubber surface, and the irregular surface profile of the DLC films. The optimum adhesion strength of $63.68 \mathrm{~N}$ was observed for Ar-Ar/DLC; this superb interfacial adhesion ensures the excellent friction performance of DLC/rubber. Furthermore, the observed stable friction curve is ascribed to the formation of a compact layer on the rubber surface after the Ar pretreatment and the formation of concave ("valley") and convex ("hill") structures on the Ar-Ar/DLC surface. Accordingly, the type of plasma used to modify the rubber surface prior to the film deposition plays an important role in the adhesion and friction performance of DLC/rubber. Moreover, the conditions of the DLC film deposition, including atmosphere components (i.e., ratio of mixture gas), pressure, ion incident energy, and plasma excitation source, significantly impact the adhesion and friction performance of DLC/rubber, which will be further explored in our future works.

\section{Acknowledgements}

This work was carried out in Youth Innovation Promotion Association CAS (No. 2017459) and the National Natural Science Foundation of China (Nos. U1737213 and 51911530114).

Electronic Supplementary Material: Supplementary material is available in the online version of this article at https://doi.org/10.1007/s40544-020-0436-6.

Open Access: This article is licensed under a Creative Commons Attribution 4.0 International
License, which permits use, sharing, adaptation, distribution and reproduction in any medium or format, as long as you give appropriate credit to the original author(s) and the source, provide a link to the Creative Commons licence, and indicate if changes were made. The images or other third party material in this article are included in the article's Creative Commons licence, unless indicated otherwise in a credit line to the material. If material is not included in the article's Creative Commons licence and your intended use is not permitted by statutory regulation or exceeds the permitted use, you will need to obtain permission directly from the copyright holder.

To view a copy of this licence, visit http://creativecommons.org/licenses/by/4.0/.

\section{References}

[1] Guo Y, Wang J, Li K. Tribological properties and morphology of bimodal elastomeric nitrile butadiene rubber networks. Mater Des 52: 861-869 (2013)

[2] Ahmed F S, Shafy M, El-megeed A A. The effect of $\gamma$-irradiation on acrylonitrile-butadiene rubber NBR seal materials with different antioxidants. Mater Des 36: 823-828 (2012)

[3] Karger-Kocsis J, Mousa A, Major Z. Dry friction and sliding wear of EPDM rubbers against steel as a function of carbon black content. Wear 264: 359-367 (2008)

[4] Dong C L, Yuan C Q, Bai X Q. Tribological properties of aged nitrile butadiene rubber under dry sliding conditions. Wear 322: 226-237 (2015)

[5] Yousif B F. Design of newly fabricated tribological machine for wear and frictional experiments under dry/wet condition. Mater Des 48: 2-13 (2013)

[6] Harsha A P, Tewari U S. Two-body and three-body abrasive wear behaviour of polyaryletherketone composites. Polym Test 22: 403-418 (2003)

[7] Erdemir A, Eryilmaz O. Achieving superlubricity in DLC films by controlling bulk, surface, and tribochemistry. Friction 2(2): 140-155 (2014)

[8] Zhang Y, Polychronopoulou K, Humood M. High temperature nanotribology of ultra-thin hydrogenated amorphous carbon coatings. Carbon 123: 112-121 (2017)

[9] Liu Y, Yu B, Cao Z. Probing superlubricity stability of hydrogenated diamond-like carbon film by varying sliding 
velocity. App Surf Sci 439: 976-982 (2018)

[10] Martin J M, Erdemir A. Superlubricity: Friction's vanishing act. Phys Today 71: 40-46 (2018)

[11] Chen X C, Li J J. Superlubricity of carbon nanostructures. Carbon 158: 1-23 (2020)

[12] Liu J Q, Li L J, Wei B, Wen F. Effect of sputtering pressure on the surface topography, structure, wettability and tribological performance of DLC films coated on rubber by magnetron sputtering. Surf Coat Technol 365: 33-40 (2019)

[13] Liu J Q, Wu Z Y, .Cao H T, Wen F. Effect of bias voltage on the tribological and sealing properties of rubber seals modified by DLC films. Surf Coat Technol 360: 391-399 (2019)

[14] Basak G C, Bandyopadhyay A, Neogi S. Surface modification of argon/oxygen plasma treated vulcanized ethylene propylene diene polymethylene surfaces for improved adhesion with natural rubber. App Surf Sci 257: 2891-2904 (2011)

[15] Bui X L, Pei Y T. Adhesion improvement of hydrogenated diamond-like carbon thin films by pre-deposition plasma treatment of rubber substrate. Surf Coat Technol 203: 1964-1970 (2009)

[16] Schenkel M, Martinez-Martinez D, Pei Y T. Tribological performance of DLC films deposited on ACM rubber by PACVD. Surf Coat Technol 205: 4838-4843 (2011)

[17] Pei Y T, Bui X L. Flexible diamond-like carbon film coated on rubber. Prog Org Coat 76: 1773-1778 (2013)

[18] Pal J P V D, Martinez-Martinez D, Pei Y T. Microstructure and tribological performance of diamond-like carbon films deposited on hydrogenated rubber. Thin Solid Films 524: 218-223 (2012)

[19] Martinez-Martinez D, Schenkel M, Pei Y T. Microstructure and chemical bonding of DLC films deposited on ACM rubber by PACVD. Surf Coat Technol 205: S75-S78 (2011)

[20] Thirumalai S, Hausberger A, Lackner J M. Anode layer source plasma-assisted hybrid deposition and characterization of diamond-like carbon coatings deposited on flexible substrates. Thin Solid Films 655: 54-61 (2018)

[21] Nagashima S, Hasebe T, Tsuya D. Controlled formation of wrinkled diamond-like carbon (DLC) film on grooved poly(dimethylsiloxane) substrate. Diam Relat Mater 22: 48-51 (2012)

[22] Pei Y T, Bui X L, Pal J P V D. Flexible diamond-like carbon films on rubber: On the origin of self-acting segmentation and film flexibility. Acta Mater 60: 5526-5535 (2012)

[23] Martinez-Martinez D, Schenkel M, Pei Y T. Microstructural and frictional control of diamond-like carbon films deposited on acrylic rubber by plasma assisted chemical vapor deposition. Thin Solid Films 19: 2213-2217 (2011)

[24] Pei Y T, Eivani A R, Zaharia T. High throughput deposition of hydrogenated amorphous carbon coatings on rubber with expanding thermal plasma. Surf Coat Technol 245: 74-83 (2014)

[25] Erdemir A. The role of hydrogen in tribological properties of diamond-like carbon films. Surf Coat Technol 146: 292-297 (2001)

[26] Pei Y T, Bui X L, De Hosson J T M. Deposition and characterization of hydrogenated diamond-like carbon thin films on rubber seals. Thin Solid Films 518: S42-S45 (2010)

[27] Thirumalai S, Hausberger A, Lackner J M. Effect of the type of elastomeric substrate on the microstructural, surface and tribological characteristics of diamond-like carbon (DLC) coatings. Surf Coat Technol 302: 244-254 (2016)

[28] Lubwama M, Corcoran B, Sayers K. Adhesion and composite micro-hardness of DLC and Si-DLC films deposited on nitrile rubber. Surf Coat Technol 206: 4881-4886 (2012)

[29] Kaczorowski W, Gajewski K R. Evaluation of mechanical properties of carbon coatings synthesised in radio frequency plasma on PDMS. Surf Coat Technol 333: 220-228 (2017)

[30] Bai C N, Liang A M, Cao Z Y, Qiang L, Zhang J Y. Achieving a high adhesion and excellent wear resistance diamond-like carbon film coated on NBR rubber by Ar plasma pretreatment. Diam Relat Mater 89: 84-93 (2018)

[31] Segu D Z. NBR surface modification by Ar plasma and its tribological properties. Ind Lubr Tribol 68: 227-232 (2016)

[32] Maia J V, Pereiraa F P. Influence of gas and treatment time on the surface modification of EPDM rubber treated at afterglow microwave plasmas. App Surf Sci 285: 918-926 (2013)

[33] Cui J, Qiang L, Zhang B. Mechanical and tribological properties of Ti-DLC films with different Ti content by magnetron sputtering technique. App Surf Sci 258: 5025-5030 (2012)

[34] Qiang L, Gao K, Zhang L. Further improving the mechanical and tribological properties of low content Ti-doped DLC film by W incorporating. App Surf Sci 353: 
522-529 (2015)

[35] Mousinho A P, Mansano R D, Maria C S. Influence of substrate surface topography in the deposition of nanostructured diamond-like carbon films by high density plasma chemical vapor deposition. Surf Coat Technol 203: 1193-1198 (2009)

[36] Guo Y, Chaunan H F. Adhesion improvements for diamond-like carbon films on polycarbonate and polymethylmethacrylate substrates by ion plating with inductively coupled plasma. Diam Relat Mater 12:

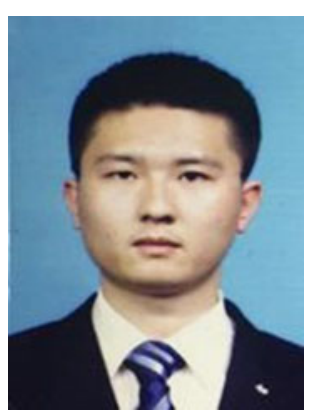

Changning BAI. He received his bachelor degree from Lanzhou University of Technology, China, 2016. He got his master degree at Lanzhou Institute of Chemical Physics, Chinese Academy of Sciences, China,

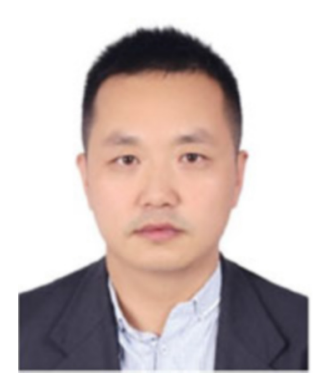

Bin ZHANG. He received his Ph.D. degree in July, 2011, from Lanzhou Institute of Chemical Physics, Chinese Academy of Sciences, and got his bachelor's degree in July, 2005, from Lanzhou University. Now he is working in Lanzhou Institute of Chemical

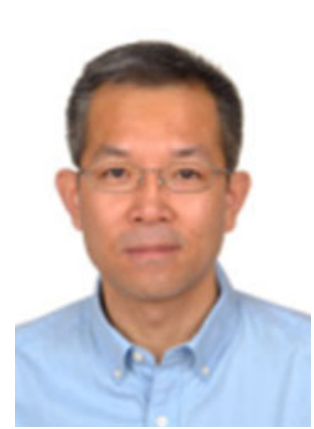

Junyan ZHANG. $\mathrm{He}$ is a professor at the Lanzhou Institute of Chemical Physics, Chinese Academy of Sciences. $\mathrm{He}$ received his bachelor degree from Lanzhou University, China, in 1990, and MS and Ph.D. degrees from the Lanzhou Institute of Chemical Physics in 1997 and 1999,
946-952 (2003)

[37] Tyczkowski J, Makowski P. Surface modification of SBS rubber by low-pressure inert gas plasma for enhanced adhesion to polyurethane adhesive. J Adhes Sci Technol 26: 841-859 (2012)

[38] Kalin M, Polajnar M. The wetting of steel, DLC coatings, ceramics and polymers with oils and water: The importance and correlations of surface energy, surface tension, contact angle and spreading. App Surf Sci 293: 97-108 (2014)

2019. Now, he continues to study for a Ph.D. degree in Lanzhou Institute of Chemical Physics, Chinese Academy of Sciences (CAS). His current scientific interests are devoted to the preparation and friction behaviors of DLC films, as well as epitaxial growth of large area multilayer hexagonal boron nitride films.

Physics, Chinese Academy of Sciences, as a professor. He has authorized the second prize of National Technological Invention (2016) and the second prize of National Scientific and Technological Progress Award (2019) and 4 other province departmental level Awards. His main interests include nanostructure films growth and its friction properties, as well as surface synergistic lubricating of liquid/solid films.

respectively. He did postdoctoral research at the University of California, Berkeley, University of Alabama, and Rice University (2000-2005). He was a guest scientist at Argonne National Laboratory (2007). He now serves as an editorial board member of Tribology Letters, Friction, Journal of Bio- \& Tribo-Corrosion. His main interests focus on graphene films and the nanostructure carbon films with super low friction. 